\title{
Non-DYT1 dystonia in a large Italian family
}

\author{
A R Bentivoglio, N Del Grosso, A Albanese, E Cassetta, P Tonali, M Frontali
}

\begin{abstract}
A large non-Jewish Italian family affected by idiopathic torsion dystonia with autosomal dominant transmission and almost complete penetrance is reported. The prevalent phenotype was characterised by early onset with cranial-cervical involvement and progression to a segmental distribution; progression to generalisation was also found. Among 45 people examined, 14 were considered definitely or probably affected by idiopathic torsion dystonia. Eight definitely affected members had mean age (SD) at onset of 15.6 (12.5); idiopathic torsion dystonia started in the cranial-cervical region in six of them, in the upper limbs in two; in four cases dystonia progressed to other body regions, in two cases a generalisation was seen. Linkage analysis with 9q34 markers excluded the region containing the DYT1 locus in this family; linkage to the doparesponsive dystonia markers was also excluded. A comparison of the phenotype in the present family and other non-DYT1 families shows striking overlapping features differing from those of DYT1 idiopathic torsion dystonia.
\end{abstract}

(F Neurol Neurosurg Psychiatry 1997;62:357-360)

Keywords: idiopathic torsion dystonia; DYT1 gene; chromosome 9

Idiopathic torsion dystonia is a neurological disorder characterised by sustained muscle contractions, often causing twisting and repetitive movements or abnormal postures, in the absence of other neurological signs and without any known cause. Three genes for well characterised forms of dystonia have been located. DYT2 for dopa responsive dystonia and DYT3 for Filipino dystonia-parkinsonism mapped on chromosomes 14 and X respectively. ${ }^{12}$ DYT1, responsible for idiopathic torsion dystonia, was mapped on chromosome 9q32-34. ${ }^{3}$ Subsequently, a small region, spanning $6 \mathrm{cM}$ and delimited by markers AK1 and ASS, was reported for the DYT1 gene, with a disease gene location closer to the telomeric boundary, as suggested by linkage dysequilibrium with ABL/ASS haplotype in Jewish families. ${ }^{4}$ Idiopathic torsion dystonia linked to $9 \mathrm{q} 34$ markers was found both in Jewish and in non-Jewish families. However, genetic heterogeneity among idiopathic torsion dystonias was reported in several families not linked to the DYT1 markers. ${ }^{5-9}$
We report here the genetic study of an Italian family affected by non-DYT1 idiopathic torsion dystonia and provide evidence that most heterogeneous families have common distinct clinical features, differing from DYT1 idiopathic torsion dystonia.

\section{Materials and methods \\ FAMILY DATA}

The family under study comprised 109 members. They were white and were ascertained through an index case seen at the movement disorders clinic of the Gemelli hospital. The ancestors were from a small countryside area close to Perugia (on the preApennine highlands) and all the family members were still living in that region.

Family members older than 18 years and participating to the study were requested to sign an informed consent. Minors were not included in the study for ethical reasons. All the examined subjects provided detailed information on the following topics: delivery, growth and development, education, past and present use of medications, drug misuse, work, pregnancies, exposure to toxins or chemicals, previous illnesses, previous admissions to hospital, any neurological or psychiatric disease, and head and body injuries. All subjects were also requested to check out a detailed list of symptoms related to dystonia or other movement disorders.

Participating family members had a complete on site neurological examination by two neurologists experienced in movement disorders (ARB, EC). To disclose dystonia, tremor, or other involuntary movements, subjects were requested to perform the following tasks (lasting for about 20 seconds each): to sit quietly, to speak trivially, to spell the alphabet, and to count quickly from 1 to 20 , to move the neck, to hold the upper limbs outstretched, to perform a finger to nose sequence, to perform rapid sequential movements with upper and lower limbs, to walk, to stand against a backward pull, to write, and to draw a spiral with either hand. Each subject was videotaped during the assessment. The on site assessors, who interviewed and examined all the available subjects, established a diagnosis of dystonia (yes, no, probable) and identified the body segments involved. A senior neurologist (AA) reviewed the videotapes (blinded on the diagnosis and on the history). When the examiners disagreed, the videotapes were re-examined jointly to reach a final decision.

The diagnosis of dystonia was considered 


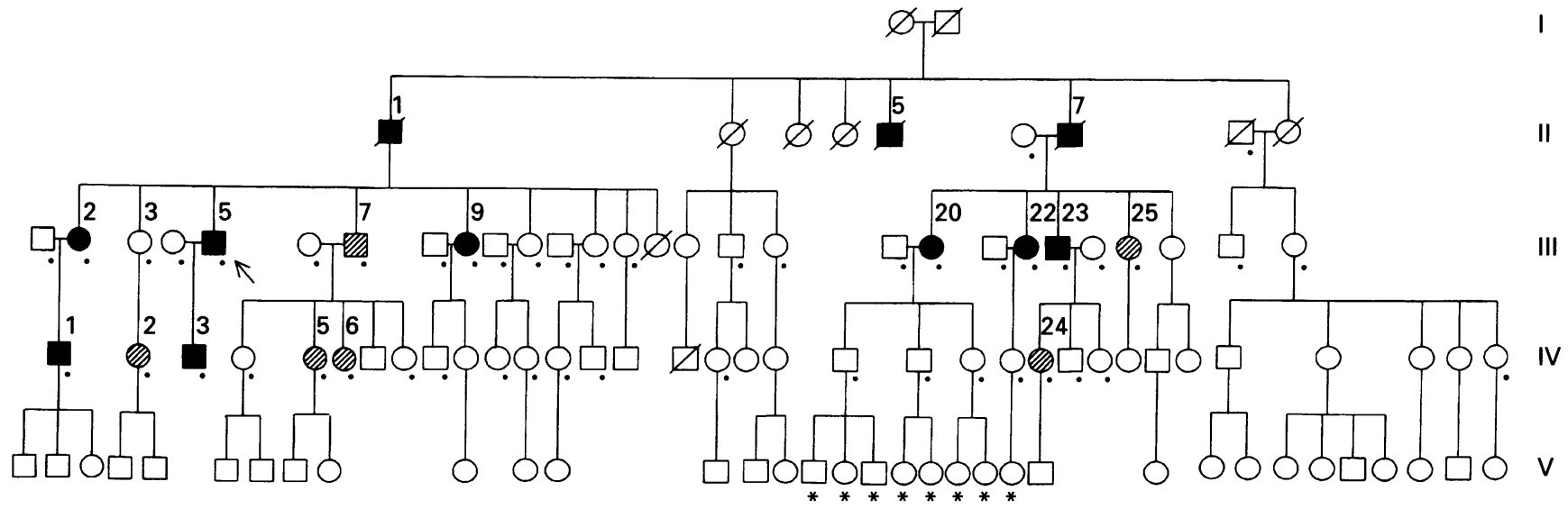

Figure 1 Pedigree of a non-fewish, Italian family with early onset idiopathic torsion dystonia. Black symbols denote affected persons; hatched symbols denote probable cases; unfilled symbols denote healthy members; dots indicate visit and blood sample for DNA analysis; asterisks indicate clinical evaluation only.

definite when dystonic posturing and slow torsion movements were evident to all the examiners. A definite diagnosis of blepharospasm was established when all the examiners found at least two prolonged spasms of the orbicularis oculi muscle. A definite diagnosis of writer's cramp was established when at least three of the following occurred: (1) a progressive change in handwriting; (2) a progressive change of hand grip; (3) hand posturing and increased pressure on the sheet during handwriting, as noted by all the evaluators; (4) abnormal contraction of brachial or antebrachial muscles during handwriting; (5) hand posturing associated with abnormal proximal movements of the arm or shoulder while writing.

The diagnosis was considered probable when unanimity could not be reached or when rapid, jerky movements were detected, but no clear dystonic postural or slow movements occurred. Excessive blinking, or mild posturing of the neck or of one arm while writing also led to a diagnosis of probable dystonia. Isolated postural or action tremor was not considered a dystonia phenotype.

DNA ANALYSIS

Blood samples were taken from thirty seven family members and 11 spouses; DNA was extracted by standard methods. Five cases of GT polymorphism, GSN, D9S60, D9S63, ASS, and D9S64 were analysed as described, ${ }^{10}{ }^{11}$ using ${ }^{35} \mathrm{~S}-\mathrm{dGTP}$ instead of ${ }^{32} \mathrm{P}$ -
dCTP. Pairwise and multipoint linkage analyses were performed using the LINKAGE package $^{12}$ assuming autosomal dominant inheritance with $50 \%$ and $75 \%$ penetrance respectively before and after the age of 24 . Although penetrance of idiopathic torsion dystonia in non-Jewish families was estimated at between $0 \cdot 30^{13} 14$ and $0 \cdot 75,{ }^{3}$ the highest value was considered in the present family since penetrance seemed to be almost complete at age 25 (fig 1). Alleles were reduced according to Ott. ${ }^{15}$

\section{Results \\ CLINICAL FEATURES}

Figure 1 shows the pedigree of the family. Inheritance of the disease was clearly autosomal dominant with a possible case of reduced penetrance (III:3 being the healthy parent of a subject with probable dystonia). We examined 56 subjects, including 45 family members and 11 spouses, of whom 37 and 11 respectively, had blood samples taken. Eight children were also examined but not sampled; they were unaffected and are not reported further.

Twenty three subjects had no signs of dystonia; their mean (SD) age was $43.3(17 \cdot 2)$ (range 18-74) years. Some of them showed an isolated postural or action tremor.

Eight subjects received a diagnosis of definite idiopathic torsion dystonia (table 1). Their mean age at the time of study was $56 \cdot 8$ (SD 12.7). Age at onset was 15.6 (SD 12.5).

Table 1 Clinical features of subjects affected by idiopathic torsion dystonia (ITD)

\begin{tabular}{|c|c|c|c|c|c|}
\hline \multirow{2}{*}{$\begin{array}{l}\text { Subject } \\
(\operatorname{sex})\end{array}$} & \multirow[b]{2}{*}{$I T D$} & \multicolumn{2}{|c|}{ At onset } & \multicolumn{2}{|c|}{ At time of evaluation } \\
\hline & & Age & Presentation & Age & Presentation \\
\hline \multicolumn{6}{|l|}{ Definite cases: } \\
\hline III:2 (F) & Segmental & 5 & Cranial-cervical & 71 & Cranial-cervical, upper limbs \\
\hline III:5 (M) & Segmental & 10 & Cervical & 67 & Cranial-cervical, upper limbs \\
\hline III:9 (F) & Segmental & 26 & Cranial-cervical & 63 & Cranial-cervical, upper limbs \\
\hline III: $20(\mathrm{~F})$ & Generalised & 5 & Upper limbs & 61 & Cranial-cervical, trunk, limbs \\
\hline III: $22(\mathrm{~F})$ & Segmental & 5 & Cervical & 59 & Cranial-cervical, trunk \\
\hline III:23 (M) & Generalised & 20 & Cervical & 56 & Cranial-cervical, limbs \\
\hline IV: $1(M)$ & Focal & 40 & Right upper limb & 45 & Right upper limb \\
\hline IV:3 (M) & Segmental & 14 & Cranial-cervical & 32 & Cranial-cervical \\
\hline \multicolumn{6}{|l|}{ Probable cases: } \\
\hline III:7 (M) & Segmental & & Cervical & 64 & Cervical, larynx, right upper limb \\
\hline III: 25 (F) & Segmental & & Cervical & 52 & Cranial-cervical, right upper limb \\
\hline IV:2 (F) & Segmental & & Upper limbs & 47 & Upper limbs \\
\hline IV:5 (F) & Focal & & Cervical & 31 & Cervical \\
\hline IV:6 (F) & Focal & & Cervical & 29 & Cervical \\
\hline IV: $23(F)$ & Focal & & Cervical & 29 & Cervical \\
\hline
\end{tabular}


Table 2 Pairwise lod scores for idiopathic torsion dystonia and $9 q$ markers with data of condition $A$

\begin{tabular}{|c|c|c|c|c|c|c|c|}
\hline \multirow[b]{2}{*}{ Marker } & \multicolumn{7}{|l|}{$\Theta$} \\
\hline & $00 \cdot 00$ & 0.01 & 0.05 & $0 \cdot 10$ & $0 \cdot 20$ & $0 \cdot 30$ & 0.40 \\
\hline $\begin{array}{l}\text { GSN } \\
\text { D9S60 } \\
\text { D9S63 } \\
\text { D9S64 }\end{array}$ & $\begin{array}{l}-6 \cdot 00 \\
-5 \cdot 68 \\
-5 \cdot 20 \\
-4 \cdot 88\end{array}$ & $\begin{array}{l}-2.84 \\
-1.30 \\
-1.49 \\
-1.68\end{array}$ & $\begin{array}{l}-1.90 \\
-0.64 \\
-0.79 \\
-1.00\end{array}$ & $\begin{array}{l}-1.34 \\
-0.43 \\
-0.52 \\
-0.76\end{array}$ & $\begin{array}{l}-0.69 \\
-0.32 \\
-0.35 \\
-0.57\end{array}$ & $\begin{array}{l}-0.36 \\
-0.28 \\
-0.27 \\
-0.40\end{array}$ & $\begin{array}{l}-0.16 \\
-0.17 \\
-0.14 \\
-0.17\end{array}$ \\
\hline
\end{tabular}

The average duration of disease was $41 \cdot 3$ (SD $21 \cdot 2$ ) (range 5-66) years. Table 1 shows the main clinical features. Most subjects (six out of eight) had their first symptom in the cervical or cranial-cervical segment, and two in the upper limbs, including a focal onset (writer's cramp) and a segmental onset (both upper limbs). All the patients with more than 18 years of duration of disease had a progression of dystonia to other body regions, and just two cases had a generalisation with a relatively mild clinical picture which did not impair daily living activities. No progression was seen in two subjects with a shorter history of the disease. The proband and subiect III:22 (who had the most severe clinical presentation) were treated with levodopa/benserazide $(200 / 50 \mathrm{mg}$ four times daily) for one month, without clinical benefit.

Six family members received a diagnosis of probable idiopathic torsion dystonia (table 1). Their mean age at the time of the study was $42 \cdot 3$ (SD 14.6) (range 29-64). The age at onset was unknown, as they all denied having any disease and considered the abnormal movements of the head as part of their gestures. Three subjects presented only jerky movements of the head, similar to those found in other members with a definite diagnosis; one subject presented with jerky movements of the head, vocal hoarseness, and an abnormal right hand grip. Two had mild action induced posturing and clumsiness in the upper limbs; in one of these, a mild postural abnormality of the neck was also seen.

\section{MOLECULAR GENETIC ANALYSIS}

To test whether the disease locus in this family is mapping in the same region of DYT1 gene, subjects were typed for five microsatellite markers encompassing the critical area: cen-GSN-5cM-D9S60-8cM-D9S63-1cM-ASS2cM-D9S64-tel. The marker ASS was not informative in this family and was excluded from further analysis. Pairwise and multipoint linkage analysis were performed considering the subjects with probable dystonia either as unknown phenotype (condition A) or as affected (condition B). Table 2 shows pairwise lod scores between the disease and each of the markers under condition A. No positive lod scores were obtained. More negative values were obtained under condition B (data not shown). A four point linkage analysis with the disease against a fixed map D9S60-8cMD9S63-3cM-D9S64 (fig 2) provided odds in favour of a disease location outside the D9S60-D9S64 interval greater than 10.000:1 under condition $\mathrm{A}$. When condition $\mathrm{B}$ was used the odds favouring the exclusion of the disease locus from the above mentioned interval were increased. Multipoint linkage analysis with a penetrance reduced to $30 \%$ was still excluding the gene from the D9S60-D9S64 interval with 1000:1 odds. Although the phenotype in the present family is very different from dopa responsive dystonia, and levodopa treatment in two affected family members was completely ineffective, family members were genotyped for D14S52 marker, linked to the dopa responsive dystonia gene. ${ }^{1}$ A two point linkage analysis between the disease and the marker loci produced highly negative lod scores excluding gene location from an inter-
Figure 2 Four point linkage analysis of idiopathic torsion dystonia and $9 q$ markers. Lod scores are plotted with data of condition A (see text).
Recombination (\%)

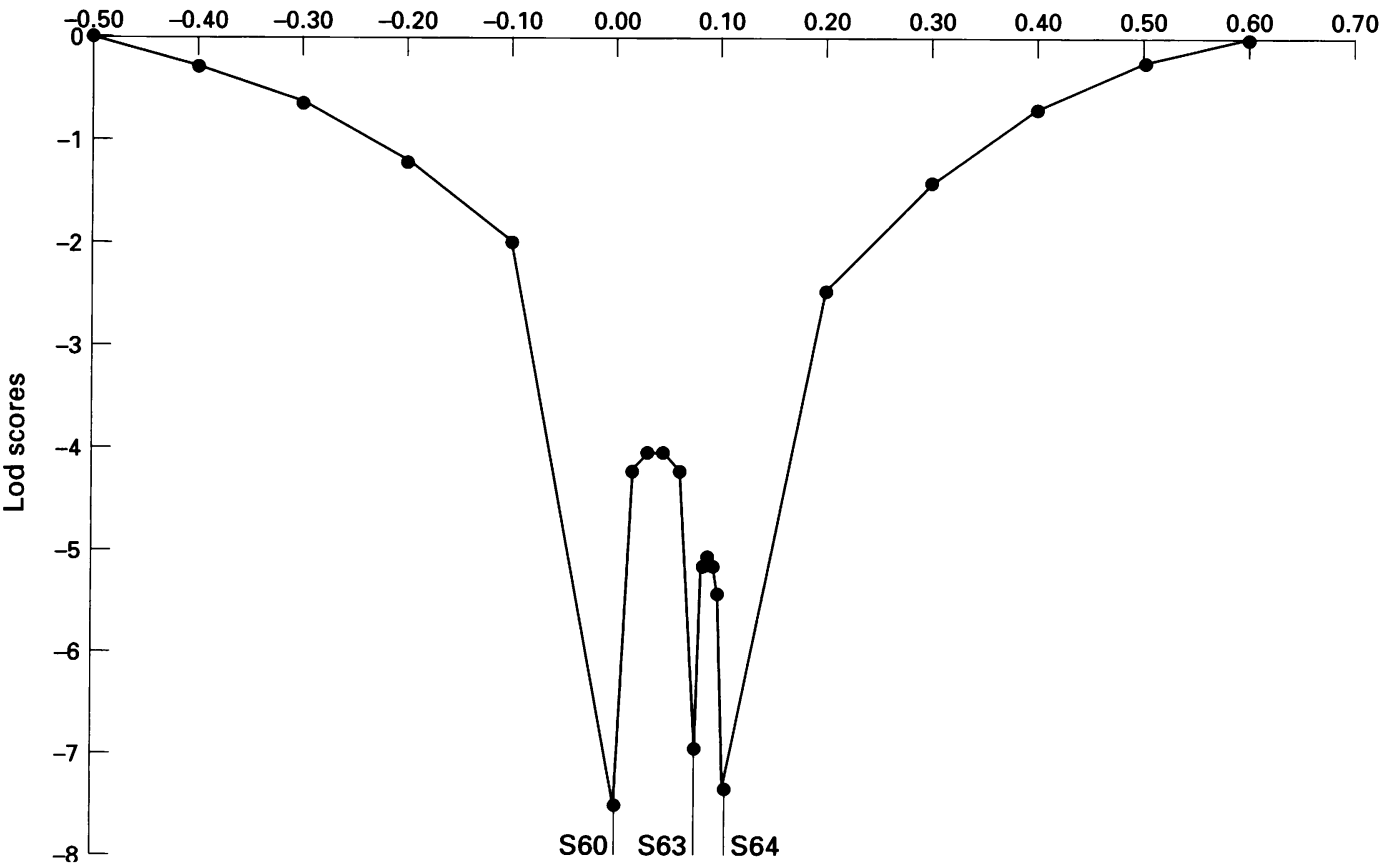


Table 3 Clinical features of cervical and upper limb idiopathic torsion dystonia in families unrelated to DYT1

\begin{tabular}{|c|c|c|c|c|c|}
\hline & Parker's & Bressman et al ${ }^{7}$ & Parker $^{8}$ & Holmgren et al ${ }^{9}$ & This family \\
\hline Definitely affected membranes & 10 & 7 & 7 & $7 \dagger$ & 8 \\
\hline Ancestry and origin & English-Australian & German-American & German-American & Swedish & Italian \\
\hline Ethnic origin & Non-Jewish & Non-Jewish & Non-Jewish & Non-Jewish & Non-Jewish \\
\hline Age at onset: mean (range) & NG $(13-37)$ & $28 \cdot 4(7-50)$ & $14 \cdot 7(5-34)$ & $27 \cdot 3(17-50)$ & $15 \cdot 6(5-40)$ \\
\hline Duration $(y)$ : mean (range) & NG & $28 \cdot 2(10-50)$ & $30 \cdot 2(10-65)$ & $14 \cdot 3(0-47)$ & $41 \cdot 3(5-66)$ \\
\hline Age at examination: mean (range) & NG & NG $(37-75)$ & NG $(15-78)$ & NG $(20-64)$ & $56 \cdot 8(32-71)$ \\
\hline \multicolumn{6}{|l|}{ Site of onset: } \\
\hline Arm & 0 & 0 & 3 & 2 & 2 \\
\hline Leg & 1 & 1 & 1 & 0 & 0 \\
\hline Neck & $9 \ddagger$ & $6 \S$ & 1 & 1 & 69 \\
\hline Cranial & 0 & 1 & 2 & 3 & 3 \\
\hline \multicolumn{6}{|l|}{ Disease progression: } \\
\hline No progression & 1 & 0 & 0 & 2 & 2 \\
\hline Progression to segmental or multifocal & 1 & 6 & 4 & 2 & 4 \\
\hline Progression to generalisation & 8 & 1 & 3 & 3 & 2 \\
\hline
\end{tabular}

^One obligate gene carrier was possibly affected by dystonia. $\uparrow$ Presenting signs were not reported in one subject affected by generalised dystonia. $\ddagger$ Dysphonia wa the presenting sign in seven subjects. $\int$ One case had cranial-cervical dystonia. $\int$ Three cases had cranial-cervical dystonia; NG $=$ not given.

val of about $3 \mathrm{cM}$ around D14S52 using condition $\mathrm{A}$, and an even larger interval using condition $\mathrm{B}$.

\section{Discussion}

We report a large Italian family affected by non-DYT1 idiopathic torsion dystonia with onset in the cranial-cervical region or in upper limbs and with slow progression to other segments and relatively mild severity.

The above results provide further evidence that idiopathic torsion dystonia is aetiologically heterogeneous and confirm previous findings that the DYT1 gene does not underlie idiopathic torsion dystonia in all families. ${ }^{5-9}$ The typical DYT1 phenotype presents with dystonia first affecting a limb (preferentially the lower limbs) during childhood or adolescence before spreading to other limbs and to axial muscles. Although DYT1 idiopathic torsion dystonia does not show a unique pattern of presentation or progression, it does not commonly affect cranial-cervical segments as the first site of onset or as a site of progression $^{316}$; however, adult onset cases with cranial-cervical presentation have been described on occasion. ${ }^{17}$ When progressing to generalisation, DYT1 idiopathic torsion dystonia is usually highly incapacitating.

Four non-Jewish idiopathic torsion dystonia families, unrelated to the DYT1 gene have been reported so far (table 3). ${ }^{5.918}$ All of them and the present one show overlapping features, distinct from DYT1 dystonia. Onset is most likely in the cranial-cervical segment or in an upper limb; with the exception of one case $^{18}$ the clinical course is relatively mild with only occasional generalisation and a very variable age at onset, on average later than that of DYT1 idiopathic torsion dystonia. However, differences among these families are also present. In particular, in most patients of the English-Australian family ${ }^{18}$ dysphonia was the presenting sign and generalisation was more common than in the other four families (including the present one). Some differences in the mean age at onset have also been reported, but variations of the age at onset were not significant when compared statistically in the four families for which these data are available (table 3 ).

On the whole, it seems that, with one exception, ${ }^{18}$ all non-DYT1 families so far described have common features, such as onset in the cranial-cervical segment or upper limb, milder course, and only occasional generalisation. The large number of meioses spanning three generations and the high penetrance of the disease make the present family a good candidate for localising a new idiopathic torsion dystonia gene, possibly responsible for the disease in the other heterogeneous families.

This research was supported by Comitato Promotore Telethon grant E 113 to AA.

1 Nygaard TG, Wilhelmsen KC, Risch NJ, et al. Linkage ygaard TG, Wilhelmsen KC, Risch NJ, et al. Linkage mapping of dopa-responsive dystonia

2 Kupke KG, Graeber MB, Müller U. Dystonia-parkinsonism syndrome (XDP) locus: flanking markers in Xq12 ism syndrome (XDP) locus: flanking ma

3 Ozelius L, Kramer PL, Moskowitz CB, et al. Human gene for torsion dystonia located on chromosome 9q32-q34. Neuron 1989;2:1427-34.

4 Ozelius L, Kramer PL, de Leon D, et al. Strong allelic association between the torsion dystonia gene (DYT1) and loci on chromosome 9q34 in Ashkenazi Jews. Am $\mathcal{f}$ Hum Genet 1992;50:619-28.

5 Ahmad F, Davis MB, Waddy HM, Oley CA, Marsden CD, Harding AE. Evidence for locus heterogeneity in autosomal dominant torsion dystonia. Genomics 1993;15:9-12.

6 Warner TT, Fletcher NA, Davis MB, et al. Linkage analysis in British and French families with idiopathic torsion in British and French families with

7 Bressman SB, Heiman GA, Nygaard TG, et al. A study of idiopathic torsion dystonia in a non-Jewish family: eviidiopathic torsion dystonia in a non-Jewish family: evi-
dence for genetic heterogeneity. Neurology 1994;44: dence 283 .

8 Bressman SB, Hunt AL, Heiman GA, et al. Exclusion of the DYT1 locus in a non-Jewish family with early-onse dystonia. Mov Disord 1994;9:626-32.

9 Holmgren G, Ozelius L, Forsgren L, et al. Adult onset idiopathic torsion dystonia is excluded from the DYT region (9q34) in a Swedish family. $f$ Neurol Neurosurg Psychiatry 1995;59:178-81.

10 Kwiatkowski DJ, Ozelius L, Kramer PL, et al. Torsion dystonia genes in 2 populations confined to a smal region on chromosome 9q32-34. Am f Hum Genet 1991; 49:366-71.

11 Kwiatkowski DJ, Enske EP, Weimer K, Ozelius L, Gusella $\mathrm{JF}$, Haines J. Construction of a GT polymorphism map of human 9q. Genomics 1992;12:229-40.

12 Lathrop GM, Lalouel J-M, Julier C, Ott J. Strategies for multilocus linkage analysis in humans. Proc Nat Acad Sci USA 1984;81:3443-6.

13 Pauls DL, Korczyn A. Complex segregation analysis of dystonia pedigrees suggests autosomal dominant inheritance Neurology 1990;40:1107-10

14 Risch NJ, Bressman SB, deLeon D, et al. Segregation analysis of idiopathic torsion dystonia in Ashkenazi Jews suggests autosomal dominant inheritance. Am $\mathcal{F}$ Hum Genet 1990;46:533-8

15 Ott J. A simple scheme for the analysis of HLA linkages in pedigrees. Ann Hum Genet 1978;42:255-7.

6 Kramer PL, de Leon D, Ozelius L, et al. Dystonia gene in Ashkenazi Jewish population is located on chromosome 9q32-34. Ann Neurol 1990;27:1 14-20.

17 Bressman SB, de Leon D, Brin MF, et al. Idiopathic dystonia among Ashkenazi Jews: evidence for autosomal dominant inheritance. Ann Neurol 1989;26:612-20.

18 Parker N. Hereditary whispering dysphonia. I Neurol Neurosurg Psychiatry 1985;48:218-24. 